experience of all students, we run the risk of perpetuating the kind of elitism we try to fight. If we want to address these two paradoxes, focusing on mobility is counterproductive. It excludes the large majority of students, and confirms the nationalist-populist argument that it is, in fact, intellectual elitism.

Inclusive and comprehensive internationalization requires us to reframe our thinking, regardless of the context we live in. Internationalization for all should be the starting point for institutional strategies, reflecting an awareness that all students must be engaged in this agenda for their future lives as citizens and as professionals.

In summary, for internationalization to be inclusive and not elitist, it must address access and equity and requires us to:

- Incorporate internationalization at home as essential to internationaliation for all.

- Recognize, value, and utilize classroom diversity, bringing alternative perspectives to study programs-from international students, those returning from mobility experiences, and students from diverse communities in the local population.

- Involve the whole institution in delivering inclusive internationalization.

- Bridge the local and the global in research, education, and service.

- Focus on regional as well as global partnerships to help deliver an inclusive internationalization agenda.

DOI: http://dx.doi.org/ıo.6oI7/ihe.20I8.94.I052I

\section{Realizing the Benefits of Massification}

\section{FAZAL RızVı}

Fazal Rizvi is professor, Global Studies in Education, University of Melbourne, Australia.E-mail:frizvi@unimelb.edu.au.

This is a revised version of a paper published in Higher Education in Southeast Asia and Beyond (HESB), a publication of the Head Foundation in Singapore.

ince the beginning of this century, systems of higher $\checkmark$ education around the world have expanded rapidly. Not only middle-income, but also low-income countries have either already become "massified"-in terms of the definition provided by Trow (2006) - or are in the process of becoming so. Higher education is experiencing an unprecedented rate of growth in gross enrollment ratios (GER). As remarkable as this success story is, it should not be assumed that "massification" is unambiguously and necessarily a good thing. While any increase in student access to higher education is a cause for celebration, massification has given rise to a range of issues that should be more widely debated.

To begin with, it needs to be recognized that growth in GER in higher education often reflects an increasing level of economic prosperity and social and political confidence within various countries. As they become integrated into the global economy, they inevitably consider the expansion of their systems of higher education as necessary for them to take advantage of the global flows of capital, the shifting modes of production, and the global supply chains. Not surprisingly, therefore, governments around the world have

Has a pool of appropriately trained aca-
demic staff been available or been pre-
pared to look after the needs of new co-
horts of students, many of whom come
from families that lack traditions of
higher learning?

been prepared to allocate large sums of public money into higher education; facilitate greater private investment in the development of new universities and colleges; and encourage the public to view an investment in higher education as an outlay that is likely to bring good returns to both the individuals and the nation.

\section{Too RapID AND AD Hoc}

In this line of thinking, massification of higher education should clearly be welcomed, since it raises a country's level of education and signals its prosperity and prestige. It is, however, important to consider whether the speed of growth in GERs has not in fact been too rapid, and its form too ad hoc. We need to ask if the respective massifying systems of higher education have been able to cope with the pace of change. To what extent has the drive toward massification been stimulated by demand rather than by proper consideration of issues of supply-by opportunism rather than systematic processes of policy analysis and development?

As the demand for higher education among the rapidly growing middle class in developing economies has grown, we need to ask what kind of job governments have done in adequately preparing their public higher education institutions (HEIs) to expand-with appropriate levels of support, resource allocation, and capacity building. Has a pool of 
appropriately trained academic staff been available or been prepared to look after the needs of new cohorts of students, many of whom come from families that lack traditions of higher learning? Most governments have tried to "soak up" demand by allowing the entry into the sector of a range of private providers with varying degrees of commitment, expertise, and resources to provide quality higher education. The approval and quality assurance processes to which these hastily established private institutions are subjected have been, at best, uneven. It is important to ask, moreover, if government bureaucracies themselves have the expertise to develop and implement the mechanisms necessary to coordinate the work of private HEIs.

The use of technology has often been considered as a viable option for meeting the growing demand for higher education at a reasonable cost. Experience around the world has shown, however, that online learning can often be much more expensive and complex than traditional "brick and mortar" education if it is to be done properly and sustainably. It is a folly to assume that pedagogic expertise in this area can be developed cheaply and quickly without sacrificing quality.

A number of universities in developing economies, both public and private, have been created as a result of rebadging or rebranding existing technical schools, polytechnics, and teachers' colleges, without any substantial shifts in the ways in which they are expected to operate, or in the types of students they recruit. Many are grossly underfunded and are widely regarded as "overcrowded factories." They lack the libraries and laboratories that any decent HEI should possess. At the same time, little is done to forge systems designed to develop academic staff professionally. While it is true that not every member of staff employed at HEIs needs to be a researcher or publish in international journals, an institution that is committed to higher learning must not be permitted to overlook its responsibility to ensure that its staff possess advanced levels of knowledge in their subject area, as well as a scholarly disposition. In this way, the task of capacity building should be regarded as central in any attempts at massification.

\section{IsSUES OF CAPACITY}

In the haste to establish new universities and expand existing ones without any substantial focus on capacity building, curriculum options at most HEIs in developing economies have inevitably been narrow, often restricted to subjects that do not require expensive laboratories, extensive libraries, and highly qualified staff. For example, programs in business and management, which are assumed to be cost effective and affordable to many new students, have in recent decades experienced explosive growth, while the number of programs in much-needed STEM areas has been limited.
As a result, there has been an oversupply of graduates in some areas, while a shortage exists in others. Many graduates, moreover, do not possess the knowledge and skills that employers consider necessary in the changing labor market geared toward the global economy. The students are often unable to secure a job in their area of study, therefore creating a risk that, in the longer term, systems of higher education might generate a legitimation and motivation crisis among their graduates. Nor will these graduates be able to make the kind of contribution to national economic development that governments hope from the massification of their systems of higher education. What this shows is that massification is not inevitably a good thing. Much depends on its purposes and outcomes, the ways it is organized and coordinated, and the contribution it is able to make to the development of the knowledge and skills needed in the global economy.

An increase in GER in higher education may thus be necessary but is not sufficient to drive economic growth and prosperity. What is required, additionally, are more comprehensive programs of higher education reform. This would involve reimagining and renewing curriculum and teaching methods, as well as the ways in which HEIs are structured and governed. Above all, it demands capacity building and adequate measures in planning and quality assurance. The question of the forms in which massification is achieved should therefore lie at the heart of debates over the expansion of systems of higher education. Broader questions about the purposes of higher learning are just as crucial, not only in relation to economic growth, but also with respect to social and cultural development. These imperatives cannot be realized by relying on emerging higher education market forces alone.

DOI: http://dx.doi.org/ıo.6oI7/ihe.2018.94.10522

\section{Universal Access to Qual- ity Tertiary Education in the Philippines}

\section{Miguel Antonio Lim, Sylvie Lomer, and Christopher MiLLORA}

Miguel Antonio Lim, University of Manchester, UK, is adviser at the Office for International Linkages of the University of the Philippines. E-mail: miguelantonio.lim@manchester.ac.uk. Sylvie Lomer is lecturer in education at the University of Manchester, UK. E-mail: sylvie. lomer@manchester.ac.uk. Christopher Millora is a PhD fellow at the University of East Anglia, UK, and a former lecturer at the University of 